University of Nebraska - Lincoln

DigitalCommons@University of Nebraska - Lincoln

Sociology Department, Faculty Publications

Sociology, Department of

$6-2009$

Hetero-Romantic Love and Heterosexiness in Children's G-Rated Films

Karin A. Martin

University of Michigan, Ann Arbor, kamartin@umich.edu

Emily Kazyak

University of Nebraska-Lincoln, ekazyak2@unl.edu

Follow this and additional works at: https://digitalcommons.unl.edu/sociologyfacpub

Part of the Sociology Commons

Martin, Karin A. and Kazyak, Emily, "Hetero-Romantic Love and Heterosexiness in Children's G-Rated Films" (2009). Sociology Department, Faculty Publications. 160.

https://digitalcommons.unl.edu/sociologyfacpub/160

This Article is brought to you for free and open access by the Sociology, Department of at DigitalCommons@University of Nebraska - Lincoln. It has been accepted for inclusion in Sociology Department, Faculty Publications by an authorized administrator of DigitalCommons@University of Nebraska - Lincoln. 
Published in Gender \& Society 23 (June 2009), pp. 315-336; doi:10.1177/0891243209335635

Copyright (C) 2009 Sociologists for Women in Society; published by SAGE Publications. http://gas.sagepub.com/content/23/3/315 Used by permission.

Published online April 21, 2009.

\title{
Hetero-Romantic Love and Heterosexiness in Children's G-Rated Films
}

\author{
Karin A. Martin and Emily Kazyak \\ University of Michigan
}

\begin{abstract}
This article examines accounts of heterosexuality in media for children. The authors analyze all the G-rated films grossing \$100 million dollars or more between 1990 and 2005 and find two main accounts of heterosexuality. First, heterosexuality is constructed through hetero-romantic love relationships as exceptional, powerful, magical, and transformative. Second, heterosexuality outside of relationships is constructed through portrayals of men gazing desirously at women's bodies. Both of these findings have implications for our understanding of heteronormativity. The first is seemingly at odds with theories that claim that heterosexuality's mundane, assumed, everyday ordinariness lends heteronormativity its power. In fact, the authors suggest heterosexual exceptionalism may extend the pervasiveness of heterosexuality and serve as a means of inviting investment in it. The second offers ways to begin to think about how heteronormativity is gendered and racialized.
\end{abstract}

Keywords: adolescence, children, sexuality, media, mass communications

The role that Disney plays in shaping individual identities and controlling fields of social meaning through which children negotiate the world is far too complex to be simply set aside as a form of reactionary politics. If educators and other cultural workers are to include the culture of children as an important site of contestation and struggle, then it becomes imperative to analyze how Disney's animated films powerfully influence the way America's cultural landscape is imagined.

-Giroux $(1996,96)$

The authors offer special thanks to Jacquelyn Richey, Hailey Mooney, and Tess Tannehill for research assistance. Thanks also to the editor and reviewers for Gender $\mathcal{E}$ Society for extremely insightful and useful comments on an earlier draft. Correspondence concerning this article should be directed to Karin A. Martin, Department of Sociology, 3001 LSA Building, University of Michigan, Ann Arbor, MI 48109-1382; e-mail: kamartin@umich.edu 
Multiple ethnographic studies suggest that by elementary school, children understand the normativity of heterosexuality. That is, by elementary school, children have a heteronormative understanding of the world (Best 1983; Renold 2002, 2005; Thorne 1993). Yet we know little about what children bring with them to the peer cultures these ethnographers describe and how these understandings develop before elementary school. Martin (2009) finds that mothers' conversations with young children normalize heterosexuality, but children's social worlds are larger than the mother-child dyad. Research on adolescence suggests that alongside parents and peers, the media are important in shaping cultural understandings of sexuality (Kim et al. 2007; Ward 1995, 2003). This article provides a beginning step toward understanding the role of the media in the development of children's heteronormativity. We ask, How are heteronormativity and heterosexuality constructed in children's top-selling G-rated movies between 1990 and 2005? Before answering this question, we sketch our understanding of heteronormativity and explain why we chose this genre of media, why we analyze the content of these films, and the limits of such analysis. We then review the existing literature on children's movies and finally turn to our study, which finds heterosexuality in children's movies is not entirely as theorists of heteronormativity describe. That is, heterosexuality within the context of romantic relationships in G-rated movies is not ordinary or mundane but, rather, is powerful, exceptional, and magical. Outside of romantic relationships, heterosexual desire is much less serious.

\section{Heteronormativity}

Heteronormativity includes the multiple, often mundane ways through which heterosexuality overwhelmingly structures and "pervasively and insidiously" orders "everyday existence" (Jackson 2006, 108; Kitzinger 2005). Heteronormativity structures social life so that heterosexuality is always assumed, expected, ordinary, and privileged. Its pervasiveness makes it difficult for people to imagine other ways of life. In part, the assumption and expectation of heterosexuality is linked to its status as natural and biologically necessary for procreation (Lancaster 2003). Anything else is relegated to the nonnormative, unusual, and unexpected and is, thus, in need of explanation. Specifically, within heteronormativity, homosexuality becomes the "other" against which heterosexuality defines itself (Johnson 2005; Rubin 1984).

But not just any kind of heterosexuality is privileged. Heteronormativity regulates those within its boundaries as it marginalizes those outside 
of it. According to Jackson (2006), heteronormativity works to define more than normative sexuality, insofar as it also defines normative ways of life in general. Heteronormativity holds people accountable to reproductive procreative sexuality and traditional gendered domestic arrangements of sexual relationships, and it is linked to particular patterns of consumerism and consumption (Ingraham 1999). In other words, while heteronormativity regulates people's sexualities, bodies, and sexual relationships (for both those nonheterosexuals on the "outside" and heterosexuals on the "inside"), it regulates nonsexual aspects of life as well.

Heteronormativity also privileges a particular type of heterosexual. Among those aspects desired in heterosexuals, Rubin (1984) includes being married, monogamous, and procreative. We might also include that heterosexuality is most sanctioned when it is intraracial and that other inequalities, like race and class, intersect and help construct what $\mathrm{Ru}$ bin calls "the inner charmed circle" in a multitude of complicated ways (e.g., Whose married sex is most sanctioned? Whose reproductive sex is most normal?). Heteronormativity also rests on gender asymmetry, as heterosexuality depends on a particular type of normatively gendered women and men (Jackson 2006). In this article, we examine how children's movies construct heterosexuality to better understand what information is available in media that might contribute to children's heteronormative social worlds.

\section{Children, Media, and Movies}

The media are an important avenue of children's sexual socialization because young children are immersed in media-rich worlds. Thirty percent of children under three years old and 43 percent of four- to six-yearolds have a television in their bedrooms, and one-quarter of children under six years old have a VCR/DVD player in their bedrooms (Rideout, Vandewater, and Wartella 2003). Since the deregulation of television in the 1980s, there has been more and more content produced on television for children. Children's programming produced for television, however, must still meet educational regulations. Films produced with young children as a significant intended portion of the audience are under no such obligations. However, to attract young children (and their parents) to films, filmmakers must get their movies a G-rating. Film producers are interested in doing this because the marketing advantages that accompany a successful children's film are enormous (Thomas 2007). The Motion Picture Association of America rates a film G for "General Audience" if the film "contains nothing in theme, language, nudity, sex, violence or other 
matters that, in the view of the Rating Board, would offend parents whose younger children view the motion picture. . . No nudity, sex scenes or drug use are present in the motion picture" (Motion Picture Association of America 2009). Thus, a G-rating signals that these films expect young children in their audience.

We examine the top-selling G-rated movies to challenge the idea that these movies are without (much) sexual content and the notion that young children are therefore not exposed to matters relating to sexuality. As theorists of heteronormativity suggest, heterosexuality is pervasive, and we want to examine how it makes its way into films that are by definition devoid of sexuality. If heteronormativity structures social life well beyond the sexual arena, then it is likely at work even in films that announce themselves as free of sexuality.

We look at movies themselves rather than children's reception of them because of the difficulty of research with young children generally, especially around issues of sexuality (Martin, Luke, and VerduzcoBaker 2007) and around media (Thomas 2007). Parents, human subjects review boards, and schools all serve as barriers to research with children on these topics. Given that we know little about how heteronormativity is constructed for children, examining the content of these films seems a logical first step before asking what children take from them. Although we will not be able to say whether or which accounts of heteronormativity children take away with them after watching these movies, current research about children's relationships to such movies indicates that children are engaged with these media and the stories they tell. Enormous numbers of children watch Disney and other G-rated children's movies. In a 2006 survey of more than 600 American mothers of three- to six-year-olds, only 1 percent reported that their child had not seen any of the films we analyze here; half had seen 13 or more (Martin, Luke, and Verduzco-Baker 2007).

Many children also watch these movies repeatedly (Mares 1998). The advent of videos made it possible for children to watch and rewatch movies at home. In fact, preschool children enjoy watching videos/DVDs repeatedly, and this has implications for the way they comprehend their messages. Crawley et al. (1999) discovered that children comprehended more from repeated viewing. Repeated viewing may also mean that jokes or innuendo intended for adults in these films may become more visible and curious, if not more intelligible, to young children. Further work by Schmitt, Anderson, and Collins (1999) also suggests that young children's attention is most focused and content best understood when watching media that includes animation, child characters, nonhuman characters, 
animals, frequent movement, and purposeful action (as opposed to live action; adults, especially adult men; and characters who only converse without much action). These are prominent features of most of the Grated films we analyze here, suggesting that they are certainly vehicles for children's attention and comprehension.

We also know young children are engaged by many such films as the plots and toys marketed from them are used in many creative ways in children's fantasy and play. Not only do movies make social worlds visible on screen, but the mass marketing surrounding these movies invites young people to inhabit those worlds (Giroux 1996). These media not only offer what is normal but also actively ensure that children understand it and compel them to consume it (Schor 2004). Researchers have demonstrated the depth of children's engagement with such media and how they adapt it for their own uses. For example, Hadley and Nenga (2004) find that Taiwanese kindergartners used everything from Snow White to Digimon to demonstrate and challenge their Confucian values at school. Gotz et al. (2005) similarly find that eight-year-old children across the United States, Israel, Germany, and South Korea make use of the media in constructing the "fantasylands" they imagine and play in. Thus, while we must look at particular groups of children's reception of particular media to see what they do with it (Tobin 2000), there is evidence that children certainly incorporate such media into their learning and play.

Finally, with respect to heterosexuality specifically, there is some evidence that suggests even young children learn from media accounts. Kelley, Buckingham, and Davies (1999) find that six- to eleven-year-old children incorporate what they learn about sexuality on television into their talk and identity work in their peer groups. Martin (2009) finds mothers of children ages three to six years old suggest that children, especially girls, know about heterosexual falling in love, weddings, and marriage from "movies," "princesses," and "Disney." Again, our research cannot address what children take away from their repeated viewings of such movies, but given that the extant research suggests they take something, we analyze what is there for the taking.

Some scholarship has begun to look at what kinds of narratives, accounts, and images are available in children's movies, and especially in Disney movies. Most useful for our purposes is the research on gender (Thompson and Zerbinos 1995; Witt 2000) and on gender and race stereotypes in young children's media (Giroux 1996; Hurley 2005; Mo and Shen 2000; Pewewardy 1996; Witt 2000). Most of this research indicates that there are fewer portrayals of women and of nonwhites and that those 
portrayals often rely on stereotypes. Analyses of the stereotypes and discourses of race and gender sometimes embed some discussion of sexuality within them. A smattering of research on race examines how some racial/ ethnic groups are portrayed as exoticized and more sexualized than white women (Lacroix 2004). Research that examines gender construction in the media sometimes links heterosexuality and romantic love to femininity and discusses the importance of finding a man/prince for the heroines (Junn 1997; Thompson and Zerbinos 1995). But heterosexuality is a given in such analyses. The existing research does not fully analyze how heterosexuality is constructed in these films.

In a different vein, media scholars have offered queer readings of some children's and especially Disney films (Byrne and McQuillan 1999; Griffin 2000). Employing a poststructuralist lens that privileges the radically indeterminate meaning of texts, Byrne and McQuillan (1999) highlight how certain characters and story lines in Disney movies can be read as queer. They discuss the many queer or ambiguous characters populating these films, such as Quasimodo and the gargoyles in The Hunchback of Notre Dame. They describe the character Mulan as a "transvestite bonanza," representing "Disney's most sustained creation of lesbian chic" $(1999,143)$. Moreover, they highlight the queerness of certain story lines in Disney movies. For instance, they argue that homosocial desire and bonds between men structure many of the films, and they explicate the queerness of the portrayal of monstrous desire, a desire that threatens the family unit, in Beauty and the Beast. These readings do not argue that particular characters or plots are gay or lesbian per se; rather, they emphasize their queer potential. Similarly, Griffin (2000) aims to queer Disney by analyzing how gay and lesbian viewers might understand these films with gay sensibilities. He highlights how Disney characters who do not fit into their societies echo the feeling of many gays and lesbians. He also argues that many characters (especially villains) lend themselves to queer readings because of how they overperform their gender roles. Villainesses often look like drag queens, such as Ursula in The Little Mermaid, a character modeled after the transvestite star Divine. These analyses rest on the desire to destabilize the meanings of characters and story lines in movies to open them up and discover their queer potential. This scholarship, however, presumes a sophisticated and knowledgeable reader of culture. It does not consider children as the audience or address whether such readings are possible for young children. It overlooks, for example, that while there are transvestite characters like $\mathrm{Mu}-$ lan, the Mulan toys marketed to children were feminine, long-haired, non-sword-wielding ones (Nguyen 1998), perhaps making such read- 
ings less sustainable for children even if they are possible. Again, we will need research on what children take away from such media to address these issues.

\section{Our Research}

In this article, we do not aim to do a queer reading of these films as such readings have already been done. Instead, we analyze how heterosexuality is constructed in children's G-rated films. We ask not how characters might be read as queer but what accounts these films offer of heterosexuality and how such accounts serve heteronormativity. Unpacking the construction of heterosexuality in these films is a first step toward understanding what social-sexual information is available to the children who watch them.

\section{Sample And Method}

The data for this study come from all the G-rated movies released (or rereleased) between 1990 and 2005 that grossed more than \$100 million in the United States (see Table 1).1 Using this sample of widely viewed films overcomes the limitations of previous analyses of children's, and especially Disney, movies, which often focus on a few particular examples. Here we have tried to examine all the most viewed films within this genre and time period. The films in our sample were extremely successful and widely viewed, as evidenced by their sales numbers in theaters. Home videos/DVDs sales and rentals of these films are also very high (Arnold 2005), including direct-to-video/DVD sequels of many of these films, for example, Lion King 1.5, Ariel's Beginning, and Beauty and the Beast's Enchanted Christmas. While the audience for these films is broader than children, children are certainly centrally intended as part of the audience. $G$ is the rating given to films that contain nothing that "would offend parents whose younger children view the motion picture" according to the Motion Picture Association of America (2009). Sixteen (80 percent) of these films are animated, and 17 are produced by Disney, a major producer of children's consumption and socialization (Giroux 1997).

After collecting this sample, the first author screened all the films and then trained three research assistants to extract any story lines, images, scenes, songs, or dialogue that depicted anything about sexuality, including depictions of bodies, kissing, jokes, romance, weddings, dat- 


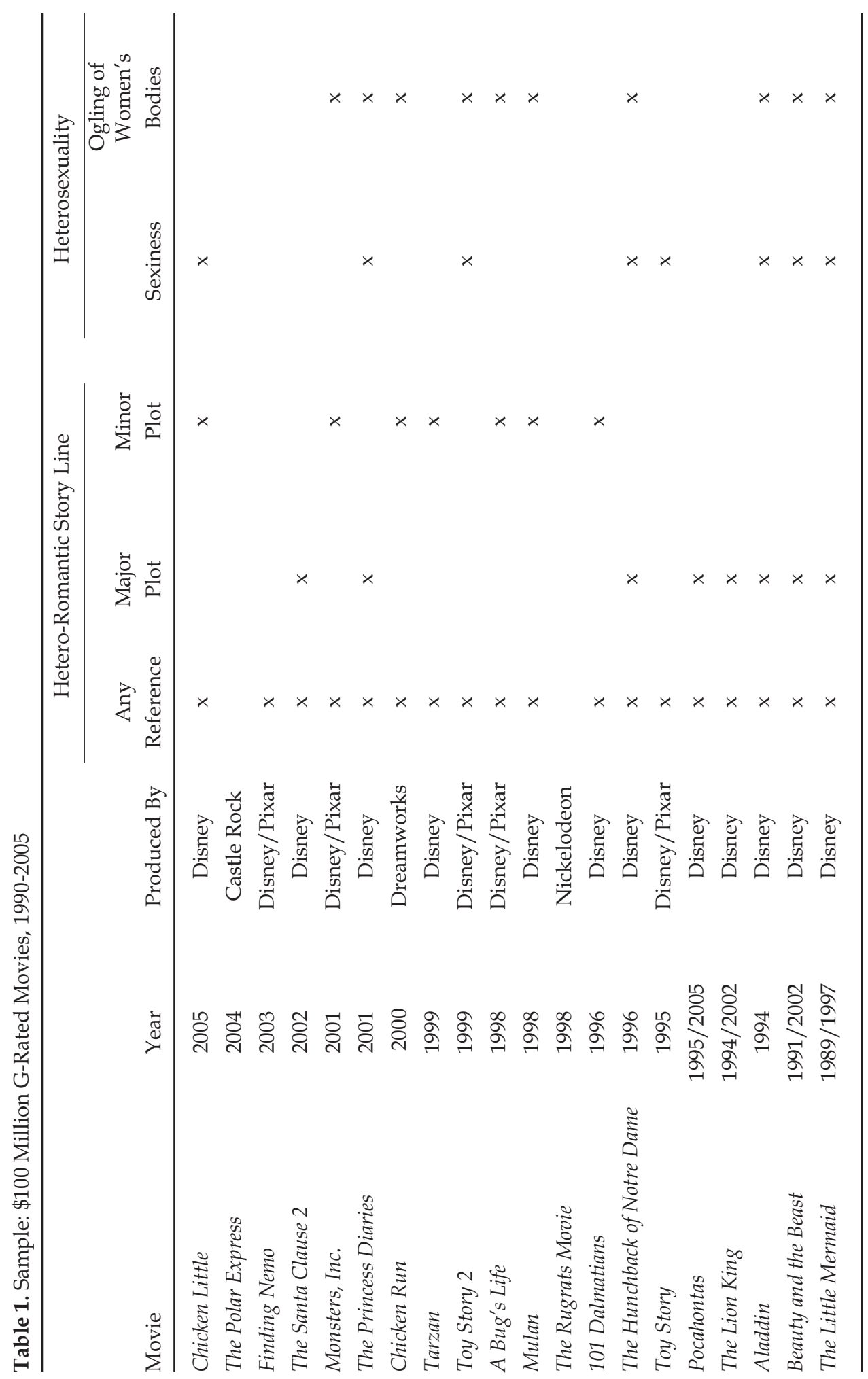


ing, love, where babies come from, and pregnancy. The research assistants then wrote descriptions of the scenes in which they found material related to sexuality. They described the visuals of the scenes in as vivid detail as possible and transcribed the dialogue verbatim. Two research assistants watched each film and extracted the relevant material. The first author reconciled the minimal differences between what each research assistant included by rescreening the films herself and adding or correcting material.

This text describing the material in each film was then inductively coded using the qualitative software program QSR-Nvivo. The themes that emerged from this open-coding were then developed in a series of initial and then integrative memos. The movies were re-viewed again by both authors as needed to further explicate the categories of understanding that emerged from first round coding. The memos were then developed into the results below (Emerson, Fretz, and Shaw 1995).

\section{Results and Discussion}

We describe two ways that heterosexuality is constructed in these films. The primary account of heterosexuality in these films is one of heteroromantic love and its exceptional, magical, transformative power. Secondarily, there are some depictions of heterosexuality outside of this model. Outside of hetero-romantic love, heterosexuality is constructed as men gazing desirously at women's bodies. This construction rests on gendered and racialized bodies and is portrayed as less serious and less powerful than hetero-romantic love.

\section{Magical, Exceptional, Transformative Hetero-Romantic Love}

Hetero-romantic love is the account of heterosexuality that is most developed in these films. Only two films have barely detectable or no heteroromantic references (see Table 1). In eight of these films hetero-romance is a major plot line, and in another seven films it is a secondary story line. Those films not made by Disney have much less hetero-romantic content than those made by Disney.

Films where we coded hetero-romantic love as a major plot line are those in which the hetero-romantic story line is central to the overall narrative of the film. In The Little Mermaid, for instance, the entire narrative revolves around the romance between Ariel, a mermaid, and Eric, a human. The same is true of movies like Beauty and the Beast, 
Aladdin, and Santa Claus 2. There would be no movie without the hetero-romantic story line for these films. In others, the hetero-romantic story line is secondary. For example, in Chicken Run the romance develops between Ginger and Rocky as they help organize the chicken revolt - the heart of the movie - although the movie ends with them coupled, enjoying their freedom in a pasture. While removing the hetero-romantic story line would still leave other stories in place in such films, the romance nonetheless exists. In other movies, like Toy Story, references are made to hetero-romance but are not developed into a story line. For instance, this film suggests romantic interest between Woody and Little Bo Peep, but their romance is not woven throughout the film.

While our focus is on the construction of heterosexuality, we recognize that other stories exist in these films. For instance, there are stories about parent-child relationships (e.g., Chicken Little wants his father to be proud of him; Nemo struggles against his overprotective father). Stories about workers, working conditions, and collective revolt also appear, for instance, in Monsters, Inc. (whose characters, working for the city's power company that relies on scaring children to generate electricity, successfully stop an evil corporate plan to kidnap children and eventually change their policy to making children laugh) and Chicken Run (whose main character, Ginger, successfully organizes all of her fellow chickens to escape their farm after learning of the farmers' plan to begin turning them into chicken pies). Though certainly there is much analysis that could be done around such stories, we do not do so here. Rather, we turn our attention to the hetero-romantic story lines and the work they do in constructing heterosexuality.

Theorists of heteronormativity suggest that the power of heteronormativity is that heterosexuality is assumed, mundane, ordinary, and expected. In contrast, we find that in these films, while it is certainly assumed, heterosexuality is very often not ordinary or mundane. Rather, romantic heterosexual relationships are portrayed as a special, distinct, exceptional form of relationship, different from all others. Characters frequently defy parents, their culture, or their very selves to embrace a hetero-romantic love that is transformative, powerful, and (literally) magical. At the same time, these accounts are sometimes held in tension with or constructed by understandings of the naturalness of heterosexuality. Below, we describe how the films construct these relationships as distinct, set apart, and different from others. We also describe how they are constructed as powerful, transformative, and magical. 
These films repeatedly mark relationships between cross-gender lead characters as special and magical by utilizing imagery of love and romance. Characters in love are surrounded by music, flowers, candles, magic, fire, ballrooms, fancy dresses, dim lights, dancing, and elaborate dinners. Fireflies, butterflies, sunsets, wind, and the beauty and power of nature often provide the setting for-and a link to the naturalness of - hetero-romantic love. For example, in Beauty and the Beast, the main characters fall in love frolicking in the snow; Aladdin and Jasmine fall in love as they fly through a starlit sky in Aladdin; Ariel falls in love as she discovers the beauty of earth in The Little Mermaid; Santa and his eventual bride ride in a sleigh on a sparkling snowy night with snow lightly falling over only their heads in Santa Claus 2; and Pocahontas is full of allusion to water, wind, and trees as a backdrop to the characters falling in love. The characters often say little in these scenes. Instead, the scenes are overlaid with music and song that tells the viewer more abstractly what the characters are feeling. These scenes depicting hetero-romantic love are also paced more slowly with longer shots and with slower and soaring music.

These films also construct the specialness of hetero-romantic love by holding in tension the assertion that hetero-romantic relationships are simultaneously magical and natural. In fact, their naturalness and their connection to "chemistry" and the body further produce their exceptionalness. According to Johnson (2005), love and heterosexuality become interwoven as people articulate the idea that being in love is overpowering and that chemistry or a spark forms the basis for romantic love. These formulations include ideas about reproductive instincts and biology, and they work to naturalize heterosexuality. We see similar constructions at work in these G-rated movies where the natural becomes the magical. These films show that, in the words of Mrs. Pots from Beauty and the Beast, if "there's a spark there," then all that needs to be done is to "let nature take its course." However, this adage is usually not spoken. Rather, the portrayal of romantic love as occurring through chemistry or a spark is depicted by two characters gazing into each other's eyes and sometimes stroking each other's faces. The viewer usually sees the two characters up close and in profile as serious and soaring music plays as this romantic chemistry is not explained with words but must be felt and understood via the gazing eye contact between the characters. Disney further marks the falling in love and the triumphs of hetero-romantic love by wrapping the characters in magical swirls of sparks, leaves, or fireworks as they stare into each other's eyes. The music accompanying such scenes is momentous and triumphant. 
We asked whether all sorts of relationships might be magical, special, and exceptional in similar ways, as it is possible that many types of relationships have these qualities in these imaginative fantasies where anything is possible. However, we found that romantic heterosexual relationships in G-rated movies are set apart from other types of relationships. This serves to further define them as special and exceptional. All other love relationships are portrayed without the imagery described above. The pacing of friendship scenes is also faster and choppier, and the music is quicker and bouncy. Nor do friendships and familial relationships start with a "spark."

Parent-child relationships are portrayed as restrictive, tedious, and protective. The child is usually escaping these relationships for the exciting adolescent or adult world. Friendships are also set aside as different from romantic love. There are many close friendships and buddies in these stories, and none are portrayed with the imagery of romantic love. Crossgender friends are often literally smaller and a different species or object in the animated films, thus making them off limits for romance. For example, Mulan's friend is Mushoo, a small, red dragon; Pocahontas is friends with many small animals (a raccoon; a hummingbird); Ariel is looked after by Sebastian (a crab) and Flounder (a fish); and Belle is befriended by a range of small household items (teapot, candlestick, broom). Same-sex friendships or buddies are unusual for girls and women unless the friends are maternal (e.g., Willow in Pocahontas, Mrs. Pots in Beauty and the Beast). The lead male characters, however, often have comical buddies (e.g., Timon in The Lion King, Abu in Aladdin, the gargoyles in The Hunchback of Notre Dame, Mike in Monsters, Inc.). These friendships are often portrayed as funny, silly, gross, and fun but certainly not as serious, special, powerful, important, or natural. For example, in The Lion King, Timon (a meerkat), Pumba (a boar), and Simba (a lion) all live a carefree life together in the jungle as the best of friends, but Simba quickly deserts them for Nala, a female lion, once he is an adolescent. Throughout the film, Timon and Pumba provide comic relief from the serious business of the lions falling in (heterosexual) love and saving the kingdom. Thus, the construction of friendships and family relationships reveal that hetero-romantic relationships in contrast are serious, important, and natural.

Furthermore, while friendships provide comic relief and friends and family are portrayed as providing comfort or advice to lead characters, these relationships are not portrayed as transformative, powerful, or magical. Hetero-romantic love is exceptional in these films because it is constructed as incredibly powerful and transformative. Throughout many of 
these films with a primary plot about hetero-romantic love, such love is depicted as rebellious, magical, defiant, and with a power to transform the world. This is quite different from our understanding of heterosexuality as normative, ordinary, and expected. The hetero-romantic relationships in these films are extraordinary. Falling in heterosexual love can break a spell (Beauty and the Beast) or cause one to give up her identity (The Little Mermaid). It can save Santa Claus and Christmas (Santa Claus 2). It can lead children (e.g., Ariel, Jasmine, Pocahontas, Belle) to disobey their parents and defy the social rules of their culture (e.g., Jasmine, Pocahontas). It can stop a war that is imminent (Pocahontas) or change an ageold law (Aladdin).

Hetero-romantic love is constructed as being in a realm of freedom and choice, a realm where chemistry can flourish and love can be sparked and discovered. Thus, romantic love is so exceptional it is positioned "outside of the control of any social or political force" (Johnson 2005, 37). This construction appears in G-rated movies and intertwines race and heteronormativity as characters who are nonwhite critique arranged marriages as backward and old-fashioned and celebrate a woman's ability to choose her own husband. For example, in Aladdin, Jasmine protests the law that dictates that she must marry a prince and says, "The law is wrong. ... I hate being forced into this . . if I do marry, I want it to be for love." Later, Aladdin agrees with her that being forced to be married by her father is "awful." Pocahontas faces a similar dilemma, as her father insists that she marry Kocoum. When she disagrees and asks him, "Why can't I choose?" he says, "You are the daughter of the chief ... it is your time to take your place among our people." While arranged marriages are portrayed as something outdated, these characters "choose" whom they will love, thus simultaneously securing hetero-romantic love's naturalness and extraordinariness and its position beyond the prescriptions of any social-political context. In fact, their love changes these prescriptions in both of these examples. Jasmine and Aladdin's love overturns the age-old law that the princess must marry a prince when she is of age, and Pocahontas's love for John Smith ends the war between her tribe and colonizers. This transformative power of hetero-romantic love is echoed throughout these films.

Finally, we observe that hetero-romantic love is not sexually embodied in these films except through kissing. The power of hetero-romantic love is often delivered through a heterosexual kiss. A lot of heterosexual kissing happens in G-rated films. Princess Diaries, with its live-action teenage characters, contains the most explicit kissing, as the main character daydreams that a boy kisses her passionately, open-mouthed 
as she falls back against the lockers smiling and giggling. Most animated kisses are with closed mouths (or the viewer cannot fully see the mouths) and of shorter duration, but they are often even more powerful. Throughout these films, but especially in the animated ones, a heterosexual kiss signifies heterosexual love and in doing so is powerful. Ariel of The Little Mermaid must secure a kiss from the prince to retain her voice and her legs. In The Lion King, when Nala and Simba kiss (lick and nuzzle) as they are reunited, they not only realize their love, but Simba realizes he must return to his rightful place as king and save his family and the entire kingdom. We often see these powerful kisses first very close-up and in profile and then moving outward to show the wider world that the powerful kisses are transforming. For example, once the Beast is transformed back into a man by Belle's declaration of love, they kiss, and the entire kingdom appears to turn from winter to springtime, flowers bloom, and others who had been damaged by the same spell as the Beast are restored to their personhood.

In one case, the kiss of love initially leads to making the world worse. When Pocahontas kisses John Smith, others see them, and this leads to the death of the man Pocahontas's father wanted her to marry. Eventually, however, their love is what brings peace between the Native Americans and European colonizers. Even this negative transformation brought on by a kiss is different from kisses outside of hetero-romantic love. Take, for example, the only same-gender kiss in these films. In The Lion King, Pumba and Timon are eating dinner and sucking on opposite ends of a worm (reminiscent of the classic Lady and the Tramp spaghetti vignette). When they reach the middle, their lips touch with a smooch, and they both look toward the camera aghast, seemingly both at the deed (the "kiss") and having been "caught" by the camera. This kiss is treated as humorous and not as serious or powerful as the kisses of hetero-romantic love. Even heterosexual kisses outside of love relationships are not serious, powerful, or transformative. For example, Jasmine kisses the evil Jafar in Aladdin, but she does so to trick him. It works as a trick and distraction, but it is not powerful or transformative. Only hetero-romantic kissing is powerful in that it signifies love and in doing so can change the world.

\section{Heterosexiness and the Heterosexual Gaze: Heterosexuality Outside of Love}

Thus far, we have described how heterosexuality is constructed through depictions of hetero-romantic love relationships in these films. There is 
also heterosexuality depicted outside of romantic relationships, though this heterosexuality is quite different and more ordinary. As such, it is depicted not as earnest or transformative but as frivolous, entertaining, and crude. This nonromantic heterosexuality is constructed through the different portrayals of women's and men's bodies, the heterosexiness of the feminine characters, and the heterosexual gaze of the masculine ones.

Heteronormativity requires particular kinds of bodies and interactions between those bodies. Thus, as heterosexuality is constructed in these films, gendered bodies are portrayed quite differently, and we see much more of some bodies than others. Women throughout the animated features in our sample are drawn with cleavage, bare stomachs, and bare legs. Women of color are more likely to be drawn as young women with breasts and hips and white women as delicate girls (Lacroix 2004). Men are occasionally depicted without their shirts, such as in Tarzan; or without much of a shirt, as in Aladdin; and in one scene in Mulan, it is implied that men have been swimming naked. However, having part of the body exposed is more common among the lead women characters and among the women who make up the background of the scenes.

Women's nudity is also often marked as significant through comment or reaction. Women are often "almost caught" naked by men. For example, Mia of the Princess Diaries has her dressing area torn down by jealous girls, almost revealing her naked to a group of male photographers. Mulan bathes in a lake when she thinks she is alone, but when male soldiers come to swim, Mushoo refers to her breasts, saying, "There are a couple of things they're bound to notice," and she sneaks away. Similarly, Quasimodo accidentally stumbles into Esmeralda's dressing area, and she quickly covers up with a robe and hunches over so as not to expose herself. She ties up her robe as Quasimodo apologizes again and again and hides his eyes. However, as he exits, he glances back toward her with a smile signifying for the viewer his love for her. A glimpse of her body has made her even more lovable and desirable.

Men's bodies are treated quite differently in these films. Male bodies, to the extent they are commented on at all, are the site of jokes. Men's crotches, genitals, and backsides are funny. For example, in Hunchback of Notre Dame, a cork from a bottle of champagne flies between a man's legs and knocks him over and the man yells in pain; later in that movie, during a fight, someone says, "That's hitting a little below the belt," and the woman says, "No this is!" and aims to strike him in the groin but is deflected by a sword. A boy in Princess Diaries is doubled over in pain as a baseball hits him in the groin. This scene is played as funny and the result of another character extracting her vengeance. The Rugrats Movie is full of 
jokes and images of boys' bare bottoms and penises. There are also references in other films to "a limp noodle" (Mulan) and "a shrinky winky" (101 Dalmatians). Mushoo in Mulan also jokes about male nudity, saying, "I hate biting naked butts." Women's genitals are never mentioned or invoked in any way. Their bodies are not the sites of jokes. Rather, women's bodies become important in the construction of heteronormative sexuality through their "sexiness" at which men gaze.

Much of the sexuality that these gendered bodies engage in has little to do with heterosexual sex narrowly defined as intercourse or even behaviors that might lead to it, but rather with cultural signs of a gendered sexuality for women. These signs are found in subplots, musical numbers, humorous scenes, and scenes depicting women's bodies, rather than in the main story lines of hetero-romantic true love. Such scenes contain sexual innuendo based in gesture, movement, tone of voice, and expression. Importantly, in all cases, sexiness is depicted as something women possess and use for getting men's attention. Sexiness is more often an attribute of female characters of color (e.g., Esmeralda, Jasmine, Ursula) (Hurley 2005) and is implicitly heterosexual given that the films construct the intended spectator of this sexiness as male (Mulvey 1975).

The best example of the representation of sexiness appears in The Hunchback of Notre Dame. Esmeralda, the Gypsy female lead, is drawn with dark hair, big green eyes, a curvy body, cleavage, and a small waist. She is also drawn with darker skin than other lead Disney characters like Belle (Beauty and the Beast) and Ariel (Little Mermaid). Darker skin and hair and "exotic" features are part of the representation of heterosexual sexiness for women. Moreover, Esmeralda spends much time in this film swaying her hips and dancing "sexily" while men admire her. An early scene in the film resembles a striptease, although all the character's clothes do not come off. The scene begins with the song, "Come one, come all! Hurry, hurry, here's your chance. See the mystery and romance ... See the finest girl in France ... Make an entrance to entrance ... Dance la Esmeralda ... Dance!" Esmeralda begins to dance. She is dressed seductively, and her dancing is provocative. We then see the men who are watching her. Frollo says, "Look at that disgusting display" to which Captain replies, "YES SIR!" and opens his eyes wider. She perches in front of Frollo and then tosses her scarf around his neck, pulls him in as if she is going to kiss him, puts her lips on his nose, and then pushes his hat over his face. She dances back to the stage where she does a split in front of Quasimodo and gives him a wink. She then steals a large spear from a security guard, stabs it into the stage and begins to swing and twist around the pole. The men in the crowd are all wide-eyed, screaming and cheering, and then they all toss money on stage for her performance. 
Not all scenes with the signification of sexiness are so elaborated. When the candlestick and duster are turned back into people in Beauty and the Beast, the now-voluptuous maid prances bare-shouldered in front of the chef who stares. Throughout Aladdin, especially in fast-paced musical scenes, sexy women prance, preen, bat their eyelashes, shake their hips, and reveal their cleavage. When Genie sings to Aladdin, he produces three women with bare stomachs and bikini-like outfits who dance around him, touch him, bat their eyes at him, and kiss him. He stares at them sometimes unsure, but wide-eyed and smiling. When Prince Ali comes to ask Princess Jasmine for her hand in marriage, his parade to the castle is adorned with writhing, dancing women with bare stomachs and cleavage. Later, Jasmine sees Prince Ali as a fraud and tricks him with similarly sexy moves. Heterosexiness in Aladdin is delivered through the bodies of women of color who are exoticized.

There are a few examples of white women depicted as "sexy," although these are more delimited and do not involve the main white women/girl characters. In Princess Diaries, a group of teenage friends are shown doing many of the same things as the animated women in Aladdin. They dance, shake their hips, make faces with curled and puckered lips and squinting eyes, play with their hair, and slap their hips. In Beauty and the Beast, a man is hit on the head for talking to a largebreasted woman with cleavage and much lipstick who moves and speaks in a sexy, flirtatious manner. Toy Story 2 has a group of singing, dancing, nearly all-white Barbies who are ogled by the masculine toys. These scenes make it clear that women move and adorn their bodies and contort their faces for men.

While the women are being sexy, the (usually white) men are performing a different role as these films construct heterosexuality. As evident from some of the examples above, there is much explicit heterosexual gazing at or ogling of women's bodies in these films. Sometimes such gazing establishes that a woman is worth the pursuit of men and the fight for her that will develop the plot of the film, as in Beauty and the Beast. In an early scene in this film, when Belle walks out of a bookshop, three men who had been peering through the window turn around as if to pretend that they had not been staring. The man in the middle is then held up by the other two so that he can stare at Belle's backside as she walks away. All three men stare and then start to sing of her beauty. In other films, sexualized gazing is not so tightly attached to beauty but to the performance of heterosexual masculinity. In one instance in Chicken Run, the chickens are "exercising," and Rocky (a chicken) stares at Ginger's (a chicken) backside. She catches him, and he smiles, slyly. When the main characters refrain from overt ogling and sexual commentary, the "sidekicks" 
provide humor through this practice. For example, in Toy Story 2, Rex, Potato Head, Slinky Dog, and Piggy Bank drive through aisles of a toy store and stop at a "beach party" where there are many Barbies in bathing suits, laughing and dancing. As the male characters approach, a jackpot sound ("ching") is heard, and all four male characters' jaws drop open. Then "Tour Guide Barbie" acrobatically lands in their car and says she will help them. They all stare at her with open eyes and mouths. Mr. Potato Head recites again and again, "I'm a married spud, I'm a married spud, I'm a married spud," and Piggy Bank says, "Make room for single fellas" as he jumps over Potato Head to sit next to Barbie. They remain mesmerized by Barbie as she gives them a tour of the store.

The objectifying gaze at women's bodies is often translated into objectifying, sexist language. Girl/women characters are called doll face, chicks, cuties, baby doll, angel face, sweet cheeks, bodacious, succulent little garden snail, tender oozing blossom, temptress snake, and tramp; and the boys/men say things like "I'll give you a tune up any time" and "give her some slack and reel her in." The desiring gazes, the commentary, and the depictions of them (large eyes, staring, open mouths, sound effects, and anxiousness) are constructed as competitive and conquering or frivolous, in stark contrast to the exceptional, magical, powerful heteroromantic love described above. These depictions of heterosexual interactions have the effect of normalizing men's objectification of women's bodies and the heterosexual desire it signifies.

\section{Conclusion}

Despite the assumption that children's media are free of sexual content, our analyses suggest that these media depict a rich and pervasive heterosexual landscape. We have illustrated two main ways that Grated films construct heterosexuality. First, heterosexuality is constructed through depictions of hetero-romantic love as exceptional, powerful, transformative, and magical. Second, heterosexuality is also constructed through depictions of interactions between gendered bodies in which the sexiness of feminine characters is subjected to the gaze of masculine characters. These accounts of heterosexuality extend our understandings of heteronormativity.

First, the finding that heterosexuality is constructed through heterosexiness points to the ways that heteronormativity intersects with gender, race, and class in its constructions. While heterosexuality is normalized and expected, it takes different forms for different sorts of bodies, and this is especially true for heterosexuality outside of romantic relationships. Second, 
the finding that hetero-romantic love is depicted as exceptional, powerful, and transformative runs counter to current theoretical understandings of heteronormativity's scaffolding being the ordinary, expected, everydayness of heterosexuality. These films show heterosexuality to be just the opposite. Heterosexuality achieves a taken-for-granted status in these films not because it is ordinary, but because hetero-romance is depicted as powerful. This finding in no way negates previous understandings of heteronormativity but rather extends another theoretical tenet - that is, that heterosexuality and its normativity are pervasive. Heterosexual exceptionalism extends the pervasiveness of heterosexuality and may serve as a means of inviting investment in it. Furthermore, heterosexuality is glorified here in mass culture but is also ordinary and assumed in everyday life. Thus, its encompassing pervasiveness lends it its power. Both ordinary and exceptional constructions of heterosexuality work to normalize its status because it becomes difficult to imagine anything other than this form of social relationship or anyone outside of these bonds.

Finally, we want to again emphasize that we cannot know what understandings and interpretations children might take away from these films or how they make sense of them alongside all the other social and cultural information they acquire. Others have shown that queer readings of such films are possible for adults (Griffin 2000). Children may have their own queer readings of such films. Without future work with children directly, we cannot know. However, these films are widely viewed by many very young children who are engaged with media rich worlds. It is likely that these accounts of heterosexuality make it into their understanding of the world in some way, albeit likely with layers of misunderstanding, reinterpretation, and integration with other information. Regardless, these films provide powerful portraits of a multifaceted and pervasive heterosexuality that likely facilitates the reproduction of heteronormativity.

\section{Note}

1. http://www.washingtonpost.com/wp-srv/style/daily/movies/100million/ article.htm

\section{References}

Arnold, Thomas K. 2005. Kids' DVDs are in a growth spurt. USA Today. http:// www.usatoday.com/life/movies/news/2005-04-04-kids-dvds_x.htm 
Best, Raphaela. 1983. We've All Got Scars: What Boys and Girls Learn in Elementary School. Bloomington, IN: Indiana University Press.

Byrne, Eleanor, and Martin McQuillan. 1999. Deconstructing Disney. London: Pluto Press.

Crawley, Alisha M., D. R. Anderson, A. Wilder, M. Williams, and A. Santomero. 1999. Effects of repeated exposures to a single episode of the television program Blue's Clues on the viewing behaviors and comprehension of preschool children. Journal of Educational Psychology 91:630-37.

Emerson, Robert, Rachel Fretz, and Linda Shaw. 1995. Writing ethnographic fieldnotes. Chicago: University of Chicago Press.

Giroux, Henry A. 1996. Animating youth: The Disneyfication of children's culture. In Fugitive cultures: Race, violence, and youth. New York: Routledge.

Giroux, Henry A. 1997. Are Disney movies good for your kids? In Kinderculture: The corporate construction of childhood, edited by Shirley R. Steinberg and Joe L. Kincheloe. Boulder, CO: Westview.

Gotz, Maya, Dafna Lemish, Amy Aidman, and Hyesung Moon. 2005. Media and the make believe worlds of children: When Harry Potter meets Pokemon in Disneyland. Mahwah, NJ: Lawrence Erlbaum.

Griffin, Sean. 2000. Tinker Belles and evil queens: The Walt Disney Company from the inside out. New York: New York University Press.

Hadley, Kathryn Gold, and Sandi Kawecka Nenga. 2004. From Snow White to Digimon: Using popular media to confront Confucian Values in Taiwanese peer cultures. Childhood 11 (4): 515-36.

Hurley, Dorothy L. 2005. Seeing white: Children of color and the Disney fairy tale princess. Journal of Negro Education 74:221-32.

Ingraham, Chrys. 1999. White weddings: Romancing heterosexuality in popular culture. New York: Routledge.

Jackson, Stevi. 2006. Gender, sexuality and heterosexuality: The complexity (and limits) of heteronormativity. Feminist Theory 7:105-21.

Johnson, Paul. 2005. Love, heterosexuality, and society. London: Routledge.

Junn, Ellen N. 1997. Media portrayals of love, marriage \& sexuality for child audiences. Paper presented at the Biennial Meeting, Society for Research in Child Development, Washington, DC.

Kelley, P., D. Buckingham, and H. Davies. 1999. Talking dirty: Sexual knowledge and television. Childhood 6:221-42.

Kim, J. L., C. L. Sorsoll, K. Collins, and B. A. Zylbergold. 2007. From sex to sexuality: Exposing the heterosexual script on primetime network television. Journal of Sex Research 44:145.

Kitzinger, Celia. 2005. Heteronormativity in action: Reproducing the heterosexual nuclear family in after-hours medical calls. Social Problems 52:477-98.

Lacroix, Celeste. 2004. Images of animated others: The orientalization of Disney's cartoon heroines from The Little Mermaid to The Hunchback of Notre Dame. Popular Communication 2:213-29. 
Lancaster, Roger. 2003. The trouble with nature. Berkeley: University of California Press.

Mares, M. L. 1998. Children's use of VCRs. Annals of the American Academy of Political and Social Science 557:120-31.

Martin, Karin A. 2009. Normalizing heterosexuality: Mothers' assumptions, talk, and strategies with young children. American Sociological Review 74: 190-207.

Martin, Karin A., Katherine Luke, and Lynn Verduzco-Baker. 2007. The sexual socialization of young children: Setting the agenda for research. In Advances in group processes, vol. 6, Social psychology of gender, edited by Shelly Correll. Oxford, UK: Elsevier Science.

Mo, W., and W. Shen. 2000. A mean wink at authenticity: Chinese images in Disney's Mulan. New Advocate 13:129-42.

Motion Picture Association of America, "Film Ratings," Motion Picture Association of America, http://www.mpaa.org/FilmRatings.asp

Mulvey, Laura. 1975. Visual pleasure and narrative cinema. Screen 16:6-18.

Nguyen, Mimi. 1998. A feminist fantasia, almost. San Jose Mercury News, July 5.

Pewewardy, Cornel. 1996. The Pocahontas paradox: A cautionary tale for educators. Journal of Navajo Education 14:20-25.

Renold, Emma. 2002. Presumed innocence: (Hetero)Sexual, heterosexist and homophobic harassment among primary school girls and boys. Childhood 9:415-34.

Renold, Emma. 2005. Girls, boys, and junior sexualities: Exploring children's gender and sexual relations in the primary school. London: Routledge Falmer.

Rideout, V., E. A. Vandewater, and E. A. Wartella. 2003. Zero to six: Electronic media in the lives of infants, toddlers, and preschoolers. Washington, DC: Henry J. Kaiser Family Foundation.

Rubin, Gayle. 1984. Thinking sex: Notes for a radical theory of the politics of sexuality. In Pleasure and danger, edited by Carol Vance. Boston: Routledge.

Schmitt, K. L., D. R. Anderson, and P. A. Collins 1999. Form and content: Looking at visual features of television. Developmental Psychology 35:1156-67.

Schor, Juliet B. 2004. Born to buy: The commercialized child and the new consumer culture. New York: Scribner.

Thomas, Susan Gregory. 2007. Buy, buy, baby: How consumer culture manipulates parents. New York: Houghton Mifflin.

Thompson, T. L., and E. Zerbinos. 1995. Gender roles in animated cartoons: Has the picture changed in 20 years? Sex Roles: A Journal of Research 32:651-73.

Thorne, Barrie. 1993. Gender play: Girls and boys in school. New Brunswick, NJ: Rutgers University Press.

Tobin, Joseph. 2000. "Good guys don't wear hats": Children's talk about the media. Williston, VT: Teachers College Press.

Ward, L. Monique. 1995. Talking about sex: Common themes about sexuality in the prime-time television programs children and adolescents view most. Journal of Youth and Adolescence 24:595-615. 
Ward, L. Monique. 2003. Understanding the role of entertainment media in the sexual socialization of American youth: A review of empirical research. Developmental Review 23:347-88.

Witt, Susan D. 2000. The influence of television on children's gender role socialization. Childhood Education 76:322-24.

Karin A. Martin is an associate professor of sociology at the University of Michigan. She does research on gender, sexuality, bodies, and children and adolescents. She is author of Puberty, Sexuality, and the Self: Girls and Boys at Adolescence (Routledge, 1996).

Emily Kazyak is a doctoral candidate in sociology at the University of Michigan. Her research interests include gender, sexuality, social theory, and social psychology. Her dissertation examines the experiences of rural gays and lesbians to ask how geography and class shape the constructions of sexual identity. 